\title{
The Effects of Royal Jelly Acid, 10-Hydroxy-trans-2-decenoic Acid, on Neuroinflammation and Oxidative Stress in Astrocytes Stimulated with Lipopolysaccharide and Hydrogen Peroxide
}

\author{
Amira Mohammed Ali ${ }^{1,2, *(\mathbb{D})}$ and Hiroshi Kunugi ${ }^{3,4}$ (D) \\ 1 Department of Behavioral Medicine, National Institute of Mental Health, National Center of Neurology and \\ Psychiatry, 4-1-1, Ogawahigashi, Kodaira, Tokyo 187-8553, Japan \\ 2 Department of Psychiatric Nursing and Mental Health, Faculty of Nursing, Alexandria University, Smouha, \\ Alexandria 21527, Egypt \\ 3 Department of Psychiatry, Teikyo University School of Medicine, 2-11-1 Kaga, Itabashi-ku, \\ Tokyo 173-8605, Japan; hkunugi@med.teikyo-u.ac.jp \\ 4 Department of Mental Disorder Research, National Institute of Neuroscience, National Center of Neurology \\ and Psychiatry, 4-1-1, Ogawahigashi, Kodaira, Tokyo 187-8502, Japan \\ * Correspondence: mercy.ofheaven2000@gmail.com; Tel.: +81-042-346-1714
}

check for updates

Citation: Ali, A.M.; Kunugi, H. The Effects of Royal Jelly Acid,

10-Hydroxy-trans-2-decenoic acid, on

Neuroinflammation and Oxidative

Stress in Astrocytes Stimulated with Lipopolysaccharide and Hydrogen Peroxide. Immuno 2021, 1, 212-222. https: / / doi.org/10.3390/

immuno1030013

Academic Editor: Yi Pang

Received: 14 June 2021

Accepted: 6 July 2021

Published: 12 July 2021

Publisher's Note: MDPI stays neutral with regard to jurisdictional claims in published maps and institutional affiliations.

Copyright: (c) 2021 by the authors. Licensee MDPI, Basel, Switzerland. This article is an open access article distributed under the terms and conditions of the Creative Commons Attribution (CC BY) license (https:/ / creativecommons.org/licenses/by/ $4.0 /)$.

\begin{abstract}
The increased prevalence of neurodegenerative diseases, especially during the COVID-19 outbreak, necessitates the search for natural immune- and cognitive-enhancing agents. 10-Hydroxytrans-2-decenoic acid (10-H2DA), the main fatty acid of royal jelly, has several pharmacological activities. Given the fundamental role of astrocytes in regulating immune responses of the central nervous system, we used cortical astrocytes to examine the effect of 10-H2DA on the expression of genes associated with neuroinflammation and the production of neurotrophins, as well as cellular resistance to $\mathrm{H}_{2} \mathrm{O}_{2}$-induced cytotoxicity. Astrocytes, pretreated with a range of concentrations of 10-H2DA for $24 \mathrm{~h}$, were exposed to lipopolysaccharide (LPS) for $3 \mathrm{~h}$, after which the expression of proinflammatory cytokines (IL- $1 \beta$, IL- 6 , and tumor necrosis factor- $\alpha$ (TNF- $\alpha$ )) and neurotrophic factors (BDNF, GDNF, and IGF-1) was evaluated. In the absence of LPS, 10-H2DA had no significant effect on the mRNA expression of neurotrophins or cytokines except for IL-1 $\beta$, which significantly increased with low doses of 10-H2DA $(3 \mu \mathrm{M})$. 10-H2DA $(10 \mu \mathrm{M})$ pretreatment of LPS-stimulated cells did not significantly inhibit the expression of cytokine encoding genes; however, it significantly lowered the mRNA expression of GDNF and tended to decrease BDNF and IGF-1 expression compared with LPS alone. Additionally, 10-H2DA did not protect astrocytes against $\mathrm{H}_{2} \mathrm{O}_{2}$-induced oxidative stress. Our data indicate no anti-inflammatory, antioxidant, or neurotrophic effect of 10-H2DA in astrocytes undergoing inflammation or oxidative stress. The effect of IGF-1 inhibition by 10-H2DA on neuronal ketogenesis needs investigation.
\end{abstract}

Keywords: aging; 10-Hydroxy-trans-2-decenoic acid (10-H2DA); astrocytes; coronavirus disease 2019/COVID-19; GDNF; IGF-1; neuroinflammation; lipopolysaccharide; hydrogen peroxide; oxidative stress; royal jelly acid

\section{Introduction}

The incidence of neurodegenerative disorders and other age-related diseases has dramatically increased during the last few decades due to of the increased size of the aging population [1,2]. The widespread global pandemic of coronavirus disease 2019 (COVID-19) has been associated with multiorgan damage, including the central nervous system (CNS). CNS damage in acute COVID-19 patients manifest in the form of confusion, depression, anxiety, impaired memory, and insomnia [3]. Recovering patients experience persistent symptoms several months following hospital/ICU discharge [3,4]: depression (in up to $30 \%$ of patients) [5], sleep disorders (in up to $100 \%$ of patients), post-traumatic stress disorders (in up to $32 \%$ of patients) [3], and mild to moderate cognitive impairment (in up to 
$81 \%$ of patients) in patients who were cognitively intact before contracting COVID-19 [6,7]. Steroids are reported to foster tissue damage in COVID-19 patients [8]; mania and psychosis induced by steroids have been reported in a few COVID-19 patients [3]. In addition, the cytokine storm associated with COVID-19 is to blame for the inflammatory reactions and tissue damage that accompany COVID-19 infection [8-10]. Although presence of the virus causing COVID-19 in neurons does not cause neurodegeneration [1], evidence supports cytokine involvement in COVID-19-related neuropsychiatric disorders [1,7].

Neuroinflammation, which embraces increased levels of cytokines in the CNS, is a physiological response of brain cells to aging and pathological conditions, e.g., disease genes, injury, or infection [2,11]. Cytokines induce blood-brain barrier disintegration allowing increased passage of cytokines from circulation into the brain, which exaggerates central inflammation $[1,2]$. Excessive and uncontrolled neuroinflammation induces mitochondrial impairment and cellular stress, which contribute to protein misfolding and aggregation, neuronal damage, and the development of neurodegenerative disorders [1,12-14].

Lipopolysaccharide (LPS), a bacterial-derived toxin that crosses the blood-brain barrier, potently activates the innate immune system to induce neuroinflammation, neurotoxicity, and neurogenic drop $[2,15,16]$. LPS targets the electron transport chain of mitochondria resulting in mitochondrial permeability, increased production of free radicals e.g., nitric oxide species (NOS) and reactive oxygen species (ROS), diminished cellular antioxidant capacity, and heightened apoptosis [2,17]. However, the nature of the neuroinflammatory response is quite dynamic, and it does not always end with neurogenic loss; in vivo, a single LPS challenge is reported to cause a late proinflammatory response characterized by activation of microglia and astrocytes, increased levels of interleukin (IL)-6, and diminution of hippocampal neurogenesis. Furthermore, repeated intermittent injections of LPS did not elicit a late proinflammatory response or affect neurogenesis despite persistence of astrocytic activation [18].

Astrocytes, the main non-neuron brain cells that orchestrate the neurogenic microenvironment, respond to inflammatory signals in order to maintain homeostasis and repair tissue damage [2]. Reactive astrocytosis is a condition that involves cellular, molecular, and functional alterations that affect astrocytes as they respond to inflammatory stimuli [19]. The degree of astrocytic alterations depends on the severity of the insult; mild reactive astrogliosis involves cellular hypertrophy and increased expression of proinflammatory cytokines, while severe inflammatory processes induce cell proliferation and scar formation $[19,20]$

The levels of neurotrophic factors expressed by astrocytes change in response to neuroinflammation $[12,21]$. One of the main astrocyte-derived protective factors that increase during inflammation is glial cell line-derived neurotrophic factor (GDNF). GDNF is a survival factor that exerts nutritional and protective effects both in the CNS and in the periphery [21,22]. Astrocytic insulin growth factor-1 (IGF-1) acts as an anti-inflammatory molecule that can reduce astrocytes' immune-mediated response to inflammatory stimuli, and it lowers their expression of proinflammatory cytokines [20,23]. Unlike GDNF, neuroinflammation is associated with a reduction in IGF-1 expression in astrocytes. Astrocytic IGF-1 deficiency during inflammation is a direct effect of mitochondrial oxidative stress induced by inflammatory stimuli such as LPS, which can be reversed by treatment with antioxidants (e.g., glutathione and $\mathrm{N}$-acetylcysteine) [24]. In addition, proinflammatory cytokines that increase during inflammation interfere with insulin/IGF-I receptor coupling in astrocytes [25]. On the other hand, IGF-I downregulation is associated with improvement of peripheral tissue sensitivity to insulin and enhanced survival (long lifespan) [13,26].

Royal jelly (RJ) is a bioactive natural bee product that exhibits various pharmacological activities. Lipids constitute $7-18 \%$ of the RJ content. 10-Hydroxy-trans-2-decenoic acid (10-H2DA), also known as RJ acid or queen bee acid, constitutes the vast majority of RJ lipid content $(0.75 \%$ to $3.39 \%)$ [27]. $10-\mathrm{H} 2 \mathrm{DA}$ is a unique medium-chain unsaturated fatty acid that exists only in RJ, and it represents one of its main bioactive components [12,15]. 10-H2DA has been reported to increase neurogenesis—but inhibit gliogenesis-from neural 
stem/progenitor cells, promote growth of cultured neurons, protect neurons against hypoxia, and decrease depressive and anxiety-like behaviors in both unstressed and stressed mice $[2,26,27]$. The effect of $10-\mathrm{H} 2 \mathrm{DA}$ on the brain has been investigated mainly in neurons, whereas little is known about its performance in astrocytes. The current study examined the effect of 10-H2DA in cultured astrocytes with a focus on exploring its neurotrophic promoting properties and astrocytes' functional response (expression of proinflammatory cytokine genes IL-1 $\beta$, IL-6, and TNF- $\alpha$ ) under LPS-induced neuroinflammation, as well as cellular viability under $\mathrm{H}_{2} \mathrm{O}_{2}$-induced oxidative stress.

\section{Materials and Method}

\subsection{Cell Culture}

Cortical astrocytes were isolated from 1 or 2 day old pups of Wistar rats (Japan SLC, Inc., Shizuoka, Japan) according to our previous reports $[19,28]$. In short, the dissected cerebral cortex was digested with papin $(9 \mathrm{U} / \mathrm{mL}$, Sigma Aldrich, St. Louis, MO, USA) and DNase I (200 U/mL, Tokyo chemical industry Co., Ltd., Tokyo, Japan) and shaken for $20 \mathrm{~min}$ in a water bath at $37^{\circ} \mathrm{C}$. The dissociated cortical cells were cultured in a medium of complete Dulbecco's modified Eagle medium (DMEM, Thermo Fisher Scientific Inc. Waltham, MA, USA) containing $10 \%$ fetal bovine serum (FBS) and 1\% penicillinstreptomycin (Gibco) inside a $75 \mathrm{~cm}^{2}$ flask at $37{ }^{\circ} \mathrm{C}$ under humidified air containing $5 \%$ $\mathrm{CO}_{2}$ (Thermo Fisher Scientific, Waltham, MA, USA). After 6-10 days, the flask was shaken at $220 \mathrm{rpm}$ for $1 \mathrm{~h}$, and the medium was replaced with a fresh medium to remove microglia. Then, it was further shaken at $220 \mathrm{rpm}$ for $24 \mathrm{~h}$ inside an incubator at $37^{\circ} \mathrm{C}$. After that, astrocytes were detached from the flask with $0.25 \%$ trypsin and reseeded in 24-well (for realtime PCR) or 48-well (for cell viability) plates at a density of $1 \times 10^{5}$ or $2.0 \times 10^{4}$ cells/well, respectively. Cells were left to adhere to the plates inside an incubator. Once cells reached a confluency level of $80 \%$, they were pretreated with the assigned concentrations of 10-H2DA for the indicated duration $(24 \mathrm{~h}$ or $3 \mathrm{~h})$ and then stimulated with LPS $(10 \mathrm{ng} / \mathrm{mL})$ for $3 \mathrm{~h}$. All experiments involving the anti-inflammatory effects of 10-H2DA were performed in triplicate. All experiments were performed in accordance with the Guidelines for Care of Laboratory Animals of the National Center of Neurology and Psychiatry, Tokyo, Japan (Approval number \#2017019).

\subsection{Pharmacological Treatment}

LPS from E. coli O111 B4 (Sigma-Aldrich, St. Louis, MO, USA) was dissolved in sterile distilled water $(1 \mathrm{mg} / \mathrm{mL})$. LPS was applied to cultured astrocytes at a final concentration of $0.01,0.1,1,10$, and $100 \mathrm{ng} / \mathrm{mL}$. A $100 \mu \mathrm{M}$ stock solution of 10-H2DA (Tokyo Chemical Industry Co. LTD, Tokyo, Japan) was prepared in ethanol. The mixture was vortexed until the sample was completely dissolved; then, it was kept at $-30{ }^{\circ} \mathrm{C}$ until use. Several doses of $10-\mathrm{H} 2 \mathrm{DA}(1,3,10,30$, and $100 \mu \mathrm{M})$ were treated 3 or $24 \mathrm{~h}$ prior to LPS or $\mathrm{H}_{2} \mathrm{O}_{2}$ treatment. Concentrations of 10-H2DA within these ranges were decided based on a former study [29]. Control cells were treated with media; ethanol was not used as vehicle.

\subsection{Real-Time PCR}

Following media aspiration from each well, the cell monolayer was washed once with cold Dulbecco's phosphate-buffered saline (DPBS), and total RNA was extracted with TRI Reagent ${ }^{\circledR}$ (Molecular Research Center, Inc., Cincinnati, OH, USA) according to the manufacturer's protocol. The RNA concentration in each sample was measured by NanoDrop spectrophotometer (DeNovix DS-11, Scrum Inc., Cambridge, MA, USA), and samples were stored at $-80{ }^{\circ} \mathrm{C}$ until use. cDNA synthesis was performed using SuperScript ${ }^{\circledR}$ VIRO ${ }^{\text {TM }}$ cDNA synthesis kit (Thermo Fisher Scientific, Waltham, MA, USA). Real-time PCR was performed using StepOne Plus (Applied Biosystems, Carlsbad, CA, USA) with Thunderbird SYBR qPCR Mix (Toyobo, CO., Ltd., Osaka, Japan). Target mRNAs were amplified using each pair of gene-specific primers for IL-1 $\beta$, IL-6, TNF- $\alpha$, brainderived neurotrophic factor (BDNF), GDNF, and IGF-1. The mRNA levels were normalized 
relative to the glyceraldehyde-3-phosphate dehydrogenase mRNA level of each sample, and the relative expression levels of all genes were calculated.

\subsection{Cell Viability}

Astrocytes treated with 10-H2DA $(100 \mu \mathrm{M})$ for 3 and $24 \mathrm{~h}$ or $10-\mathrm{H} 2 \mathrm{DA}(10 \mu \mathrm{M})$ for $24 \mathrm{~h}$ were challenged with $\mathrm{H}_{2} \mathrm{O}_{2}(200 \mu \mathrm{M})$ (Fujifilm Wako, Osaka, Japan) for $3 \mathrm{~h}$. Then, a 3(4,5-dimethyl-2-thiazolyl)-2,5-diphenyltetrazolium bromide (MTT, Nacalai Tesque, Tokyo, Japan) assay was performed according to a previous study [19]. In brief, the medium was replaced with MTT $(0.5 \mathrm{mg} / \mathrm{mL})$ in fresh medium and incubated for $1 \mathrm{~h}$ at $37^{\circ} \mathrm{C}$. Then, the resulting formazan salt was dissolved by isopropanol containing $0.04 \mathrm{~N} \mathrm{HCl}$, after which a microplate reader was used to measure the absorbance at $570 \mathrm{~nm}$.

\subsection{Statistical Analysis}

Data are expressed as means \pm SEM for the indicated number of independently performed experiments. Statistical comparisons of data were performed in SPSS IBM version 22 by one-way ANOVA with Tukey's post hoc test. Significance was considered at probability values less than 0.05 .

\section{Results}

Treatment with LPS was used to stimulate astrocytic inflammatory response, and it markedly increased the expression of cytokine genes. However, LPS at $10 \mathrm{ng} / \mathrm{mL}$ concentration significantly stimulated the expression of all proinflammatory cytokines (IL-1 $\beta$, IL-6, and TNF- $\alpha$ ) compared with the other concentrations (Supplementary Materials, Figure $1 \mathrm{a}-\mathrm{c}$ ). Therefore, the $10 \mathrm{ng} / \mathrm{mL}$ concentration was used in all subsequent LPS treatments.

(a)

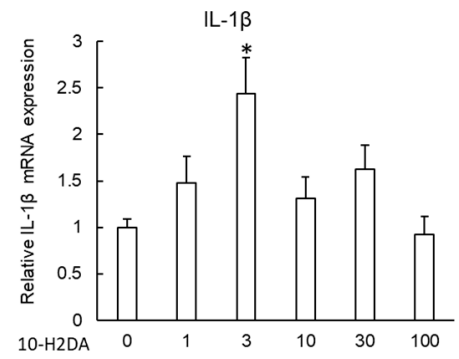

(d)

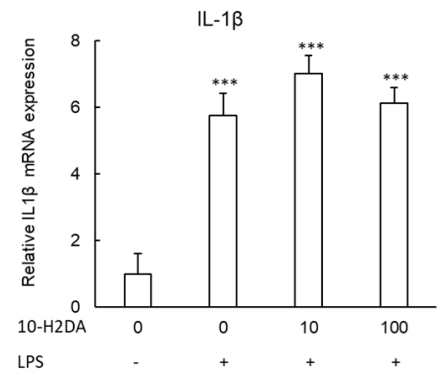

(b)

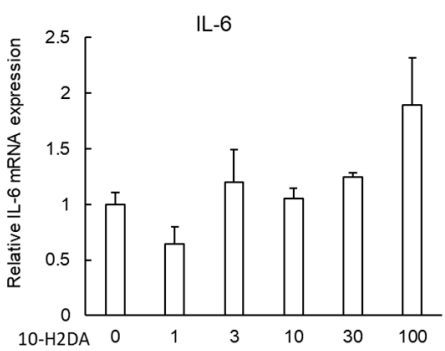

(e)

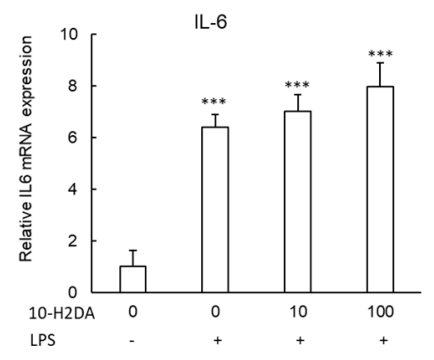

(c)

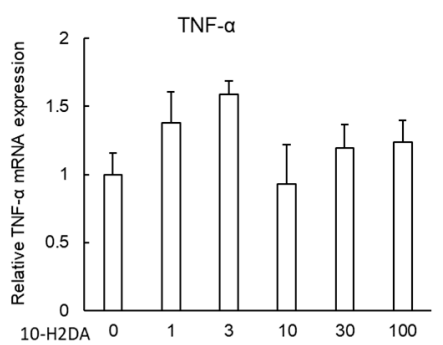

(f)

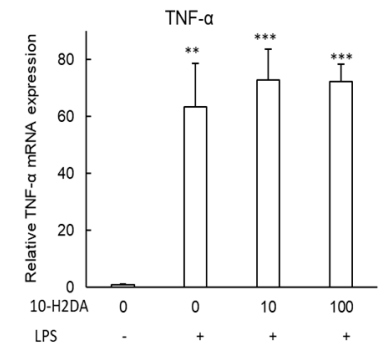

Figure 1. Effects of 10-H2DA on astrocytic expression of proinflammatory cytokines. $(\mathbf{a}-\mathbf{c})$ Astrocytes $(n=4)$ were treated with 10-H2DA alone $(0-100 \mu \mathrm{M})$ for $24 \mathrm{~h}$. $(\mathbf{d}-\mathbf{f})$ Astrocytes $(n=6)$ were treated with $10-\mathrm{H} 2 \mathrm{DA}(10 \mu \mathrm{M}$ and $100 \mu \mathrm{M})$ for $24 \mathrm{~h}$ followed by LPS $(10 \mathrm{ng} / \mathrm{mL})$ for $3 \mathrm{~h}$. Control values in (a-f) were obtained in the absence of LPS and 10-H2DA. The results are presented as means \pm SEMs. Data were analyzed by one-way ANOVA with Tukey's post hoc test; ${ }^{*} p<0.05$ versus control cells. ${ }^{* *}$ : significance at $0.01,{ }^{* * *}$ : significance at 0.001 compared with untreated cells. LPS treatment is indicated by + and absence of LPS is indicated by -. 


\subsection{The Effect of 10-H2DA on the Expression of Proinflammatory Cytokine Genes}

To determine the optimal and the safest 10-H2DA concentrations to be used for further experiments, RT-qPCR was performed to examine the expression of proinflammatory cytokines after incubating astrocytes with 10-H2DA for $24 \mathrm{~h}$ in the absence of LPS. Treatment with different concentrations of 10-H2DA $(0,1,3,10,30$, and $100 \mu \mathrm{M})$ for $24 \mathrm{~h}$ did not cause any significant changes in the levels of proinflammatory cytokines except for low doses $(3 \mu \mathrm{M})$, which significantly increased the expression of IL-1 $\beta(p=0.011)$ compared with untreated control cells. According to the findings indicated in Figure 1a-c, two concentrations of 10-H2DA $(10 \mu \mathrm{M}$ and $100 \mu \mathrm{M})$ were chosen for subsequent experiments. Whereas LPS alone significantly enhanced the transcription of inflammatory-related genes, 10-H2DA pretreatment of LPS-stimulated cells exhibited no significant inhibition of the expression of IL-1 $\beta$, IL-6, and TNF- $\alpha$ compared with solo LPS treatment, as shown in Figure 1d-f.

\subsection{The Effect of 10-H2DA on the Expression of Neurotrophic Factors}

Treatment with different concentrations of 10-H2DA $(0,1,3,10,30$, and $100 \mu \mathrm{M})$ for $24 \mathrm{~h}$ did not cause any significant changes in the levels of BDNF, GDNF, and IGF-1 except for one dose $(3 \mu \mathrm{M})$, which tended to decrease the expression of IGF-1 compared with untreated control cells $(p=0.103)$ (Figure $2 \mathrm{c})$. 10-H2DA $(10 \mu \mathrm{M}$ and $100 \mu \mathrm{M})$ decreased the expression of BDNF compared with LPS treatment alone. Astrocytes treated with LPS alone or with a combination of 10-H2DA $(100 \mu \mathrm{M})$ and LPS demonstrated a significant increase in the mRNA expression of GDNF-related gene compared with untreated control cells $(p=0.000$ and 0.005 , respectively). However, GDNF expression levels were significantly lower in astrocytes pretreated with 10-H2DA $(10 \mu \mathrm{M}, p=0.013)$ compared with cells treated with LPS alone; no significant difference was noted between both doses of 10-H2DA $(p=0.419)$. 10-H2DA $(10 \mu \mathrm{M}$ and $100 \mu \mathrm{M})$ pretreated astrocytes that were stimulated with LPS demonstrated a tendency toward decreased expression of IGF-1 compared with complete absence of treatment in control cells ( $p=0.117$ and 0.088 , respectively).

(a)

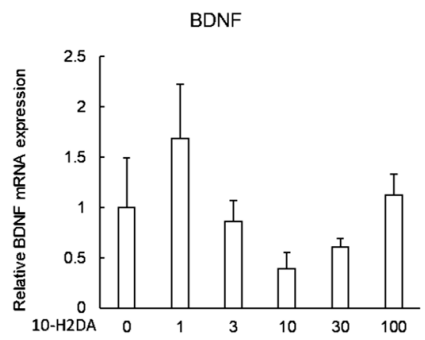

(d)

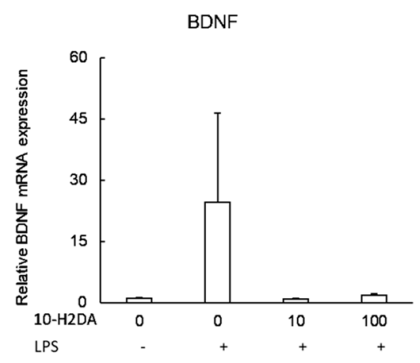

(b)

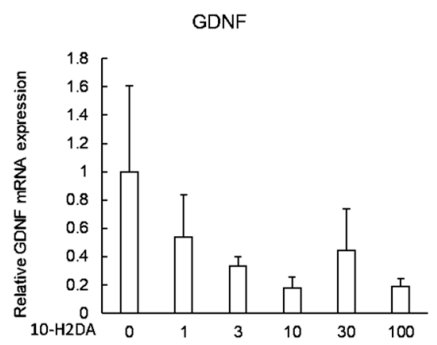

(e)

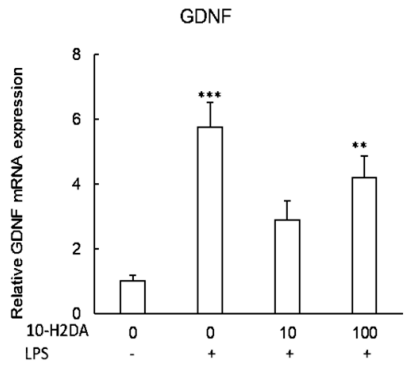

(c)

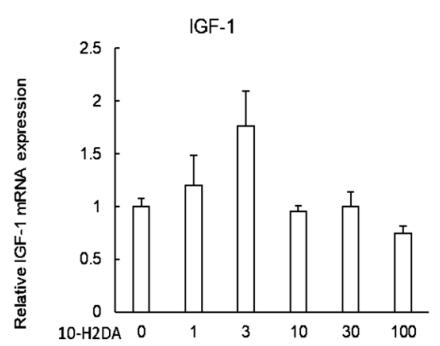

$(\mathbf{f})$

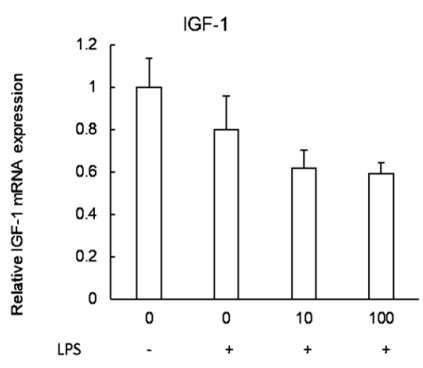

Figure 2. Effects of 10-H2DA on astrocytic expression of neurotrophic factors. $(\mathbf{a}-\mathbf{c})$ Astrocytes $(n=4)$ were treated with 10-H2DA $(0-100 \mu \mathrm{M})$ for $24 \mathrm{~h}$. $(\mathbf{d}-\mathbf{f})$ Astrocytes $(n=6)$ were treated with $10-\mathrm{H} 2 \mathrm{DA}(10 \mu \mathrm{M}$ and $100 \mu \mathrm{M})$ for $24 \mathrm{~h}$ followed by LPS $(10 \mathrm{ng} / \mathrm{mL})$ for $3 \mathrm{~h}$. Control values in $(\mathbf{a}-\mathbf{f})$ were obtained in the absence of LPS and 10-H2DA. The results are presented as means \pm SEMs. Data were analyzed by one-way ANOVA with Tukey's post hoc test; ${ }^{*} p<0.05$ versus control cells. ${ }^{* *}$ : significance at $0.01,{ }^{* * *}$ : significance at 0.001 compared with untreated cells. LPS treatment is indicated by + and absence of LPS is indicated by - 


\subsection{The Effect of 10-H2DA on the Cell Viability of Astrocytes Undergoing Oxidative Stress}

Treating astrocytes with $\mathrm{H}_{2} \mathrm{O}_{2}$ resulted in substantial cell death compared with control cells $(p=0.000)$ (Figure 3a,b). Treatment with 10-H2DA $10 \mu \mathrm{M}$ and $100 \mu \mathrm{M}$ for $24 \mathrm{~h}$ (Figure $3 \mathrm{a}$ ) or 10-H2DA $100 \mu \mathrm{M}$ for $3 \mathrm{~h}$ and $24 \mathrm{~h}$ (Figure $3 \mathrm{~b}$ ) did not protect astrocytes against the cytotoxicity of $\mathrm{H}_{2} \mathrm{O}_{2}$ compared with $\mathrm{H}_{2} \mathrm{O}_{2}$ control cells (all $p$-values >0.05).

(a)

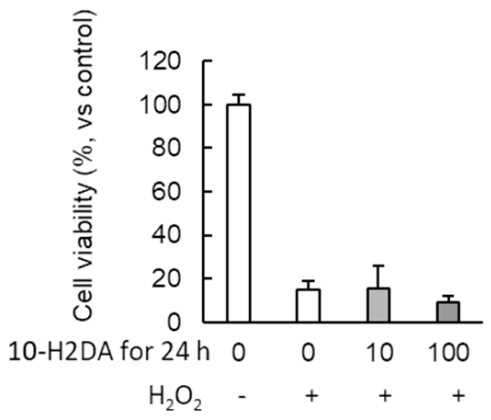

(b)

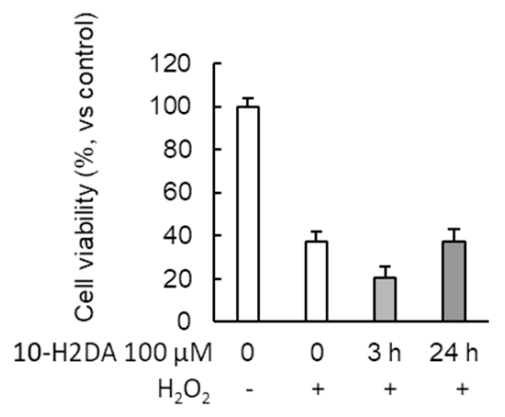

Figure 3. Effects of 10-H2DA on cell viability. (a) Astrocytes $(n=8)$ were treated with 10-H2DA $(10 \mu \mathrm{M}$ and $100 \mu \mathrm{M})$ for $24 \mathrm{~h}$. (b) Astrocytes $(n=8)$ were treated with 10-H2DA $(100 \mu \mathrm{M})$ for 3 and $24 \mathrm{~h}$. Cells were then exposed to $\mathrm{H}_{2} \mathrm{O}_{2}$-induced oxidative stress $(100 \mu \mathrm{M})$ for $3 \mathrm{~h}$. Control values in both (a) and (b) were obtained in the absence of $\mathrm{H}_{2} \mathrm{O}_{2}$ and 10-H2DA. Data represent the mean \pm SEM ( ${ }^{*} p<0.05$ vs. $\mathrm{H}_{2} \mathrm{O}_{2}$ control, one-way ANOVA followed by Tukey's post hoc test). $\mathrm{H}_{2} \mathrm{O}_{2}$ treatment is indicated by + and absence of $\mathrm{H}_{2} \mathrm{O}_{2}$ is indicated by -

\section{Discussion}

According to our knowledge, 10-H2DA has not been used in astrocytes before. The study at hand is, therefore, the first to examine the anti-inflammatory, neurotrophic, and antioxidant effects of 10-H2DA in astrocytes. The findings indicate a high degree of complexity of 10-H2DA-mediated responses in astrocytes: (1) in the absence of LPS, low doses of 10-H2DA $(3 \mu \mathrm{M})$ stimulated IL-1 $\beta$ expression and tended to decrease the transcription of IGF-1; (2) under inflammatory conditions, 10-H2DA had no inhibitory effect on LPSinduced inflammatory response but downregulated the expression of BDNF, GDNF, and IGF-1; (3) 10-H2DA did not protect astrocytes against $\mathrm{H}_{2} \mathrm{O}_{2}$-induced oxidative stress.

Astrocytes maintain homeostasis under normal physiological conditions by producing low levels of cytokines in response to byproducts of metabolic processes [30]. In the current study, low doses of 10-H2DA $(3 \mu \mathrm{M})$ increased astrocyte expression of IL- $1 \beta$ in the absence of LPS. This finding is somewhat in accordance with results reported by Chen et al. (2016) noting increased expression of IL-6 in macrophages treated with low doses of 10-H2DA [31]. In line, small amounts of a synthesized derivative of RJ lipids known as 4-hydroperoxy2-decenoic acid ethyl ester (HPO-DAEE) significantly prevented neuron death induced by 6-Hydroxydopamine via a mechanism that involved stimulating ROS production, which resulted in activation of Nrf2, a pathway that masters the production of antioxidant enzymes [32]. We can, therefore, argue that, under normal physiological conditions, low doses of 10-H2DA may represent a nonpathogenic insult that might stimulate astrocytes to produce cytokines as an attempt for neuronal protection.

In the current study, 10-H2DA acid had no inhibitory effect on LPS-induced cytokine expression in astrocytes, which is consistent with findings reported in several former studies. 10-H2DA increased TNF- $\alpha$ expression and inhibited the mRNA expression of IL10 , an anti-inflammatory cytokine that can suppress immune response, in LPS-challenged RAW264.7 macrophages compared with single LPS treatment [31]. Similarly, 10-H2DA had no inhibitory effect on LPS-stimulated IL-6 production (unpublished data cited in [33]), as well as LPS-induced interferon (IFN)- $\beta$ production, IFN regulatory factor- 1 induction, and IFN-stimulated response element activation, which are required for NOS induction $[34,35]$. 10-H2DA did not protect neurons against 6-hydroxydopamine-induced cell death [32]. 
Taken together, our results, as well as those of previous studies, imply that 10-H2DA might not suppress neuroinflammation. Nonetheless, challenging astrocytes with LPS has been indicated as a neuroinflammation model of depression [24], while oral and intraperitoneal daily administration of 10-H2DA decreased depressive and anxiety-like behaviors in mice [36,37]. Thus, these reports suggest that the mechanism underlying the antidepressant effect of 10-H2DA does not involve suppressing neuroinflammation or reducing astrocytic activation. On the other hand, 10-H2DA at a concentration of $4 \mathrm{mM}$ was reported to inhibit cytokines and activate forkhead box $\mathrm{O}$ (FOXO) transcription factor 1-mediated autophagy in LPS-challenged microglia [38]. Because that concentration was much higher than all concentrations used in the current study, the lack of effects of 10H2DA on inflammation may be because the used concentrations of 10-H2DA might not be physiologically relevant.

In this study, $10-\mathrm{H} 2 \mathrm{DA}(3 \mu \mathrm{M})$ tended to increase IGF-1 under noninflammatory conditions. However, 10-H2DA downregulated the mRNA expression of IGF-1 in LPS-treated astrocytes (though not approaching significance). Downregulation of IGF-1 increases insulin sensitivity $[13,26]$, which is likely to improve astrocytic glucose metabolism under normal conditions. The opposite may not be true for activated cells, which may have limited capacity to oxidize glucose metabolites secondary to pyruvate dehydrogenase inhibition [39]. Reduced insulin signaling promotes lifespan by blocking phosphatidylinositol $(3,4,5)$-triphosphate $\left(\mathrm{PIP}_{3}\right)$ production, resulting in inhibition of PI3K and AKT kinase activity and blockage of FOXO phosphorylation, permitting FOXO proteins to remain in the nucleus, which facilitates the transcription of genes that encode antioxidant enzymes [39]. $10-\mathrm{H} 2 \mathrm{DA}$ is reported to expresses protective effects in LPS-treated microglia via FOXO1mediated stimulation of autophagy [38]. It also demonstrated a lifespan-extending activity in Caenorhabditis elegans nematodes via IGF-1 downregulation, which is associated with the modulation of dietary restriction signaling [26]. Short-chain fatty acids similar to 10-H2DA are reported to alter mitochondrial respiratory chain in human astrocytes without lowering intracellular ATP levels or activating the energy sensor AMP-activated protein kinase. As a result, the rates of astrocytic ketogenesis increased 2.2-fold compared with control cells. Such modulation of astrocyte metabolism may activate shuttle systems that supply neighboring neurons with lactate and ketone bodies as a basic form of fuel [40]. Ketone bodies (e.g., $d-\beta$-Hydroxybutyrate) extend lifespan by mimicking calorie restriction, and the metabolism of ketone bodies modulates the redox potential of the NADP antioxidant system, a terminal destructor of free radicals [39]. Therefore, 10-H2DA-induced reduction of IGF-1 in activated astrocytes may empower mitochondria, possibly leading to increased lifespan of these cells and their surrounding neurons. Moreover, altered mitochondrial metabolism creates a degree of cellular stress, which is associated with increased production of IL-6; IL-6 stimulates the release of other cytokines [41]. Therefore, it is likely that 10-H2DA treatment might mimic the effect of repeated LPS treatment, which prevents the development of a late proinflammatory response and associated neurons loss [18]. Nevertheless, more investigations are needed to examine the feasibility of such scenarios.

In the present study, use of 10-H2DA in unchallenged astrocytes had no effect on GDNF. Treatment with LPS alone significantly increased the expression of GDNF compared with untreated control cells, which is consistent with a former study [21]. Meanwhile, cells treated with both 10-H2DA and LPS had significantly lower GDNF levels (10-H2DA 10 $\mu \mathrm{M})$ than cells treated with LPS alone. Despite the fact that GDNF is a survival factor that protects neurons during inflammation, a recent review indicates that GDNF is a strong promotor of glial proliferation and migration-an effect that is associated with glioma development [22]. Furthermore, severe neuroinflammation is associated with astrocytic proliferation [20]. Therefore, our finding indicates that moderate doses of 10-H2DA (10 $\mu \mathrm{M})$ may finetune the expression of GDNF during neuroinflammation in a fashion that promotes its contribution to neurons survival and prevents astrocytic proliferation and migration. It seems that BDNF is less likely to be involved in the therapeutic activities of $10-\mathrm{H} 2 \mathrm{DA}$ in activated astrocytes; its levels dropped considerably in LPS-challenged cells 
that were pretreated with 10-H2DA $(10 \mu \mathrm{M}$ and $100 \mu \mathrm{M})$ compared with LPS alone. It is not clear why such a reduction in BDNF occurred.

Reports on the antioxidant properties of 10-H2DA are mixed. 10-H2DA was reported to prevent cellular death and increase properly polarized mitochondria in neurons challenged with glutamate and hypoxia compared with untreated controls [37]. On the contrary, Inoue et al. (2018) indicated that lipids of RJ (10-H2DA, 10-hydroxydecanoic acid, and sebacic acid) failed to counteract 6-hydroxydopamine-induced cellular death in human neuroblastoma SH-SY5Y cell cultures. However, one of their derivatives, HPO-DAEE, significantly prevented cell death and stimulated the production of antioxidant enzymes such as heme oxygenase-1 [32]. Our data revealed no antioxidant effect of 10-H2DA against $\mathrm{H}_{2} \mathrm{O}_{2}$-induced cell death, which is consistent with the results of Inoue et al. (2018). It is likely that 10-H2DA induced mitochondrial impairment [40], which is associated with increased cellular stress [41], at least during the acute phase, before a condition of cellular accommodation would take place. Such effects would promote the depletion of IGF-1 receptors in astrocytes, leading to further structural and functional distortions of mitochondria and increased mitochondrial ROS production, which may render astrocytes more sensitive to $\mathrm{H}_{2} \mathrm{O}_{2}$-induced cytotoxicity [42].

\section{Conclusions}

Our findings indicate that 10-H2DA may not directly alleviate neuroinflammation nor counteract oxidative stress in activated astrocytes. However, it may modulate astrocytic metabolism and prevent the development of a late inflammatory response and associated neurogenic loss. It also might play a role in finetuning the expression of GDNF under inflammatory conditions.

Supplementary Materials: The following are available online at https:/ /www.mdpi.com/article/10 .3390/immuno1030013/s1, Figure S1: Effects of LPS treatment on astrocytic production of proinflammatory cytokines.

Author Contributions: Conceptualization, H.K. and A.M.A.; methodology, H.K. and A.M.A.; software, A.M.A.; validation, H.K. and A.M.A.; writing-original draft preparation, A.M.A.; writingreview and editing, H.K.; supervision, H.K.; project administration, H.K.; funding acquisition, H.K. All authors have read and agreed to the published version of the manuscript.

Funding: This study was partially supported by the Strategic Research Program for Brain Sciences from Japan Agency for Medical Research and development, AMED, Japan (Grant No. 18dm0107100h0003).

Institutional Review Board Statement: The study was conducted according to the guidelines of the Declaration of Helsinki, and approved by the Institutional Review Board of the National Center of Neurology and Psychiatry, Tokyo, Japan (Approval number \#2017019).

Informed Consent Statement: Not applicable.

Data Availability Statement: Data is available from the corresponding author upon request.

Acknowledgments: The authors thank Shingo Nakajima for his help with the administrative and experimental procedures supporting the current study.

Conflicts of Interest: The authors declare no conflict of interest. 


$\begin{array}{ll}\text { Abbreviations } \\ \text { 10-H2DA } & \begin{array}{l}\text { 10-Hydroxy-trans-2-decenoic acid } \\ \text { BDNF }\end{array} \\ \text { Brain-derived neurotrophic factor } \\ \text { CNS } & \begin{array}{l}\text { Coronavirus disease 2019 } \\ \text { Central nervous system }\end{array} \\ \text { DMEM } & \text { Dulbecco's modified Eagle medium } \\ \text { DPBS } & \text { Dulbecco's phosphate-buffered saline } \\ \text { FBS } & \text { Fetal bovine serum } \\ \text { FOXO } & \text { Forkhead box O transcription factor } \\ \text { GDNF } & \text { Glial cell line-derived neurotrophic factor } \\ \text { IFN } & \text { Interferon } \\ \text { IGF-1 } & \text { Insulin growth factor-1 } \\ \text { IL } & \text { Interleukin } \\ \mathrm{H}_{2} \mathrm{O}_{2} & \text { Hydrogen peroxide } \\ \text { LPS } & \text { Lipopolysaccharide } \\ \text { NOS } & \text { Nitric oxide species } \\ \text { RJ } & \text { Royal jell } \\ \text { ROS } & \text { Reactive oxygen species } \\ \text { TNF- } \alpha & \text { Tumor necrosis factor- } \alpha\end{array}$

\section{References}

1. Iodice, F.; Cassano, V.; Rossini, P.M. Direct and indirect neurological, cognitive, and behavioral effects of COVID-19 on the healthy elderly, mild-cognitive-impairment, and Alzheimer's disease populations. Neurol. Sci. 2021, 42, 455-465. [CrossRef] [PubMed]

2. Ali, A.M.; Kunugi, H. Royal jelly as an intelligent anti-aging-A focus on cognitive aging and Alzheimer's disease: A review. Antioxidants 2020, 9, 937. [CrossRef]

3. Rogers, J.P.; Chesney, E.; Oliver, D.; Pollak, T.A.; McGuire, P.; Fusar-Poli, P.; Zandi, M.S.; Lewis, G.; David, A.S. Psychiatric and neuropsychiatric presentations associated with severe coronavirus infections: A systematic review and meta-analysis with comparison to the COVID-19 pandemic. Lancet Psychiatry 2020, 7, 611-627. [CrossRef]

4. Nakamura, Z.M.; Nash, R.P.; Laughon, S.L.; Rosenstein, D.L. Neuropsychiatric Complications of COVID-19. Curr. Psychiatry Rep . 2021, 23, 25. [CrossRef] [PubMed]

5. Tomasoni, D.; Bai, F.; Castoldi, R.; Barbanotti, D.; Falcinella, C.; Mulè, G.; Mondatore, D.; Tavelli, A.; Vegni, E.; Marchetti, G.; et al. Anxiety and depression symptoms after virological clearance of COVID-19: A cross-sectional study in Milan, Italy. J. Med. Virol. 2021, 93, 1175-1179. [CrossRef]

6. Jaywant, A.; Vanderlind, W.M.; Alexopoulos, G.S.; Fridman, C.B.; Perlis, R.H.; Gunning, F.M. Frequency and profile of objective cognitive deficits in hospitalized patients recovering from COVID-19. Neuropsychopharmacology 2021, 1-6. [CrossRef]

7. Mazza, M.G.; Palladini, M.; De Lorenzo, R.; Magnaghi, C.; Poletti, S.; Furlan, R.; Ciceri, F.; Rovere-Querini, P.; Benedetti, F. Persistent psychopathology and neurocognitive impairment in COVID-19 survivors: Effect of inflammatory biomarkers at three-month follow-up. Brain Behav. Immun. 2021, 94, 138-147. [CrossRef]

8. Ali, A.M.; Kunugi, H. Skeletal muscle damage in COVID-19: A call for action. Medicina 2021, 57, 372. [CrossRef] [PubMed]

9. Ali, A.M.; Kunugi, H. Propolis, bee honey, and their components protect against coronavirus disease 2019 (Covid-19): A review of in silico, in vitro, and clinical studies. Molecules 2021, 26, 1232. [CrossRef] [PubMed]

10. Ali, A.M.; Kunugi, H. Approaches to nutritional screening in patients with Coronavirus Disease 2019 (COVID-19). Int. J. Environ. Res. Public Health 2021, 18, 2772. [CrossRef] [PubMed]

11. Ali, A.M.; Hendawy, A.O. So, Antidepressant Drugs have Serious Adverse Effects, but what are the Alternatives? Nov. Appro. Drug Des. Dev. 2018, 4, 555636. [CrossRef]

12. Ali, A.M.; Kunugi, H. Apitherapy for Parkinson's disease: A focus on the effects of propolis and royal jelly. Oxid. Med. Cell Longev. 2020, 2020, 1727142. [CrossRef]

13. Ali, A.M.; Kunugi, H. Intermittent fasting, dietary modifications, and exercise for the control of gestational diabetes and maternal mood dysregulation: A review and a case report. Int. J. Environ. Res. Public Health 2020, 17, 9379. [CrossRef]

14. Ali, A.M.; Ahmed, A.H.; Smail, L. Psychological Climacteric Symptoms and Attitudes toward Menopause among Emirati Women. Int. J. Environ. Res. Public Health 2020, 17, 5028. [CrossRef]

15. Ali, A.M.; Kunugi, H. Apitherapy for age-related skeletal muscle dysfunction (sarcopenia): A review on the effects of royal jelly, propolis, and bee pollen. Foods 2020, 9, 1362. [CrossRef] [PubMed]

16. Ali, A.M.; Kunugi, H. Corona Virus Disease 2019 (COVID-19): A pandemic that threatens physical and mental health by promoting physical inactivity. Sports Med. Health Sci. 2020, 2, 221-223. [CrossRef] [PubMed]

17. Canteiro, P.B.; Antero, D.C.; Tramontin, N.d.S.; Simon, K.U.; Mendes, C.; Anastácio Borges Correa, M.E.; Silveira, P.C.L.; Muller, A.P. Insulin treatment protects the brain against neuroinflammation by reducing cerebral cytokines and modulating mitochondrial function. Brain Res. Bull. 2019, 149, 120-128. [CrossRef] 
18. Perez-Dominguez, M.; Avila-Munoz, E.; Dominguez-Rivas, E.; Zepeda, A. The detrimental effects of lipopolysaccharide-induced neuroinflammation on adult hippocampal neurogenesis depend on the duration of the pro-inflammatory response. Neural Regen. Res. 2019, 14, 817-825. [CrossRef]

19. Ali, A.M.; Kunugi, H. Bee honey protects astrocytes against oxidative stress: A preliminary in vitro investigation. Neuropsychopharmacol. Rep. 2019, 39, 312-314. [CrossRef] [PubMed]

20. Acaz-Fonseca, E.; Ortiz-Rodriguez, A.; Azcoitia, I.; Garcia-Segura, L.M.; Arevalo, M.-A. Notch signaling in astrocytes mediates their morphological response to an inflammatory challenge. Cell Death Discov. 2019, 5, 85. [CrossRef] [PubMed]

21. Kronenberg, J.; Merkel, L.; Heckers, S.; Gudi, V.; Schwab, H.M.; Stangel, M. Investigation of Neuregulin-1 and Glial Cell-Derived Neurotrophic Factor in Rodent Astrocytes and Microglia. J. Mol. Neurosci. 2019, 67, 484-493. [CrossRef]

22. Zhang, L.; Wang, D.; Han, X.; Tang, F.; Gao, D. Mechanism of methylation and acetylation of high GDNF transcription in glioma cells: A review. Heliyon 2019, 5, e01951. [CrossRef]

23. Amtul, Z.; Hill, D.J.; Arany, E.J.; Cechetto, D.F. Altered Insulin/Insulin-Like Growth Factor Signaling in a Comorbid Rat model of Ischemia and $\beta$-Amyloid Toxicity. Sci. Rep. 2018, 8, 5136. [CrossRef] [PubMed]

24. Takano, K.; Koarashi, K.; Kawabe, K.; Itakura, M.; Nakajima, H.; Moriyama, M.; Nakamura, Y. Insulin expression in cultured astrocytes and the decrease by amyloid $\beta$. Neurochem. Int. 2018, 119, 171-177. [CrossRef] [PubMed]

25. Fazakerley, D.J.; Minard, A.Y.; Krycer, J.R.; Thomas, K.C.; Stöckli, J.; Harney, D.J.; Burchfield, J.G.; Maghzal, G.J.; Caldwell, S.T.; Hartley, R.C.; et al. Mitochondrial oxidative stress causes insulin resistance without disrupting oxidative phosphorylation. J. Biol. Chem. 2018, 293, 7315-7328. [CrossRef] [PubMed]

26. Kunugi, H.; Ali, A.M. Royal Jelly and Its Components Promote Healthy Aging and Longevity: From Animal Models to Humans. Int. J. Mol. Sci. 2019, 20, 4662. [CrossRef]

27. Ali, A.M.; Hendawy, A.O. Royal Jelly Acid, 10-Hydroxy-Trans-2-Decenoic Acid, for Psychiatric and Neurological Disorders: How helpful could it be? Edelweiss. J. Food Sci. Technol. 2019, 1, 1-4. [CrossRef]

28. Nakajima, S.; Numakawa, T.; Adachi, N.; Yoon, H.S.; Odaka, H.; Ooshima, Y.; Kunugi, H. The inactivation of extracellular signal-regulated kinase by glucagon-like peptide-1 contributes to neuroprotection against oxidative stress. Neurosci. Lett. 2016, 616, 105-110. [CrossRef]

29. Hattori, N.; Nomoto, H.; Fukumitsu, H.; Mishima, S.; Furukawa, S. Royal jelly and its unique fatty acid, 10-Hydroxy-trans-2decenoic acid, promote neurogenesis by neural stem/progenitor cells in vitro. Biomed. Res. 2007, 28, 261-266. [CrossRef]

30. Casedas, G.; Bennett, A.C.; Gonzalez-Burgos, E.; Gomez-Serranillos, M.P.; Lopez, V.; Smith, C. Polyphenol-associated oxidative stress and inflammation in a model of LPS-induced inflammation in glial cells: Do we know enough for responsible compounding? Inflammopharmacology 2019, 27, 189-197. [CrossRef]

31. Chen, Y.-F.; Wang, K.; Zhang, Y.-Z.; Zheng, Y.-F.; Hu, F.-L. In Vitro Anti-Inflammatory Effects of Three Fatty Acids from Royal Jelly. Mediat. Inflamm. 2016, 2016, 3583684. [CrossRef]

32. Inoue, Y.; Hara, H.; Mitsugi, Y.; Yamaguchi, E.; Kamiya, T.; Itoh, A.; Adachi, T. 4-Hydroperoxy-2-decenoic acid ethyl ester protects against 6-hydroxydopamine-induced cell death via activation of Nrf2-ARE and eIF2 $\alpha$-ATF4 pathways. Neurochem. Int. 2018, 112, 288-296. [CrossRef]

33. Sugiyama, T.; Takahashi, K.; Mori, H. Royal Jelly Acid, 10-Hydroxy-trans-2-Decenoic Acid, as a Modulator of the Innate Immune Responses. Endocr. Metab. Immune Disord. Drug Targets 2012, 12, 368-376. [CrossRef] [PubMed]

34. Takahashi, K.; Sugiyama, T.; Tokoro, S.; Neri, P.; Mori, H. Inhibition of interferon-gamma-induced nitric oxide production by 10-Hydroxy-trans-2-decenoic acid through inhibition of interferon regulatory factor-8 induction. Cell Immunol. 2012, 273, 73-78. [CrossRef]

35. Sugiyama, T.; Takahashi, K.; Kuzumaki, A.; Tokoro, S.; Neri, P.; Mori, H. Inhibitory mechanism of 10-Hydroxy-trans-2-decenoic acid (royal jelly acid) against lipopolysaccharide- and interferon-beta-induced nitric oxide production. Inflammation 2013, 36, 372-378. [CrossRef] [PubMed]

36. Ito, S.; Nitta, Y.; Fukumitsu, H.; Soumiya, H.; Ikeno, K.; Nakamura, T.; Furukawa, S. Antidepressant-Like Activity of 10-HydroxyTrans-2-Decenoic Acid, a Unique Unsaturated Fatty Acid of Royal Jelly, in Stress-Inducible Depression-Like Mouse Model. Evid. Based Complementary Altern. Med. 2012, 2012, 139140. [CrossRef] [PubMed]

37. Weiser, M.J.; Grimshaw, V.; Wynalda, K.M.; Mohajeri, M.H.; Butt, C.M. Long-Term Administration of Queen Bee Acid (QBA) to Rodents Reduces Anxiety-Like Behavior, Promotes Neuronal Health and Improves Body Composition. Nutrients 2017, 10, 13. [CrossRef]

38. You, M.; Miao, Z.; Tian, J.; Hu, F. Trans-10-Hydroxy-2-decenoic acid protects against LPS-induced neuroinflammation through FOXO1-mediated activation of autophagy. Eur. J. Nutr. 2019. [CrossRef]

39. Veech, R.L.; Bradshaw, P.C.; Clarke, K.; Curtis, W.; Pawlosky, R.; King, M.T. Ketone bodies mimic the life span extending properties of caloric restriction. IUBMB Life 2017, 69, 305-314. [CrossRef]

40. Thevenet, J.; Marchi, U.D.; Domingo, J.S.; Christinat, N.; Bultot, L.; Lefebvre, G.; Sakamoto, K.; Descombes, P.; Masoodi, M.; Wiederkehr, A. Medium-chain fatty acids inhibit mitochondrial metabolism in astrocytes promoting astrocyte-neuron lactate and ketone body shuttle systems. FASEB J. 2016, 30, 1913-1926. [CrossRef] 
41. Scheld, M.; Fragoulis, A.; Nyamoya, S.; Zendedel, A.; Denecke, B.; Krauspe, B.; Teske, N.; Kipp, M.; Beyer, C.; Clarner, T. Mitochondrial Impairment in Oligodendroglial Cells Induces Cytokine Expression and Signaling. J. Mol. Neurosci. 2019, 67, 265-275. [CrossRef] [PubMed]

42. Logan, S.; Pharaoh, G.A.; Marlin, M.C.; Masser, D.R.; Matsuzaki, S.; Wronowski, B.; Yeganeh, A.; Parks, E.E.; Premkumar, P.; Farley, J.A.; et al. Insulin-like growth factor receptor signaling regulates working memory, mitochondrial metabolism, and amyloid- $\beta$ uptake in astrocytes. Mol. Metab. 2018, 9, 141-155. [CrossRef] [PubMed] 